\title{
Assessing changes in water flow regulation in Chongqing region, China
}

\author{
Yang Xiao • Qiang Xiao • Zhiyun Ouyang • \\ Qin Maomao
}

Received: 19 March 2014 / Accepted: 10 December 2014 /Published online: 17 May 2015

(C) Springer International Publishing Switzerland 2015

\begin{abstract}
Water flow regulation is an important ecosystem service that significantly impacts on ecological quality and social benefits. With the aim of improving our understanding of ecosystems and proposing strategies for optimizing ecosystem services, a geographic information system (GIS)-based approach was designed to estimate and map regulated water flow in the Chongqing region of China. In this study, we applied the integrated valuation of environmental services and tradeoffs (InVEST) model and mathematical simulations to estimate the provision of the regulated water flow across space and time in 2000, 2005, and 2010. The results indicated that this ecosystem service had improved by $2.07 \%$ from 2000 to 2010 as a result of human activities (such as vegetation restoration) and climatic interaction. Places with positive changes mainly occurred in high mountain areas, whereas places with negative changes were mainly distributed in resettlement areas along the Yangtze River. The type of ecosystem in areas with high mountains and steep slopes was a relatively minor contributor to the total service, but this ecosystem had the higher water flow regulation
\end{abstract}

Y. Xiao $\cdot$ Q. Xiao $\cdot$ Z. Ouyang $(\bowtie) \cdot$ Q. Maomao State Key Laboratory of Urban and Regional Ecology, Research Center for Eco-Environmental Sciences, Chinese Academy of Sciences,

Shuangqing Road 18, Beijing 100085, China

e-mail: zyouyang@rcees.ac.cn

Y. Xiao

e-mail: xyrcees@163.com

Q. Xiao

e-mail: xiaoqiang7598@126.com

Q. Maomao

e-mail: 395872330@qq.com capacity. Moreover, with the increase in altitude and slope, the percentage contribution of forest increased significantly from 2000 to 2010 ; by contrast, the percentage contribution of cropland decreased rapidly. As for the impacts, the spatial variation of water flow regulation in the Chongqing region had a significant relation with climate and human activities at the regional scale. These results provided specific information that could be used to strengthen necessary public awareness about the protection and restoration of ecosystems.

Keywords Water flow regulation · GIS · Human activities $\cdot$ Climatic interaction $\cdot$ Ecosystem services

\section{Introduction}

Ecosystem services are crucial to the functioning of life on Earth (Daily 1997; Costanza et al. 1997; Guo et al. 2001; Bai et al. 2011). Water flow regulation, one of the most important ecosystem services, involves the influence of natural systems on the regulation of hydrological flow on the surface of the Earth, and is a function of the storage and retention components of the water flow (Hewlett 1982; De Groot et al. 2002). According to records, the total annual precipitation on Earth is approximately $1.19 \times 10^{4}$ billion $\mathrm{m}^{3}$. Most of the rainfall is absorbed primarily by soil, and is either then taken up by vegetation or percolates into the groundwater. However, without the regulation of this ecological system, the rain would fall directly on bare ground, reducing soil water uptake and increasing surface runoff, leading to the loss of soil and nutrients (Hillel 1991). 
Over the past decades, much progress has been made in understanding how ecosystems supply water. The "water conservation" ecosystem service provides vital information for regional ecosystem management and sustainable development, and various approaches and methods for ecosystem service evaluation have been developed extensively from case studies representing diverse spatial scales and sites (Miao et al. 2010; Zhang et al. 2010, 2011; Chen et al. 2011; Miao et al. 2011; Wang et al. 2014). However, there are few studies on the service of water flow regulation, and less attention has focused on the complicated spatial heterogeneity influenced by climate, vegetation, soil texture, terrain, and human activities, especially in the hilly areas with heterogeneous natural resources and geographic features.

Chongqing region, one of the most important ecological zones in China, is located on the upper reaches of the Three Gorges Reservoir Area (TGRA), the site of the largest dam project in the world (Zhang et al. 2009). The status of the ecosystem functions in Chongqing has direct impacts on the TGRA. Recently, rapid population growth and urban development in this region have increased the demand for food, housing, and factories (Hunter et al. 2003; Semwal et al. 2004), which have led to complex changes in ecosystem types. In addition, global changes in climate (Miao et al. 2014) have also highlighted the role of ecosystems in water flow regulation and climate change mitigation and adaption. However, there have been few studies on the quantitative estimates of the water-flow regulation and its spatial distribution characteristics.

The aim of this study was to use a new combined method including integrated valuation of environmental services and tradeoffs (InVEST) and mathematical simulations to map the water flow regulation. Moreover, we undertook a detailed analysis of the spatial and temporal variation of ecosystem services in Chongqing region and their driving forces.

\section{Study area}

The study area (Chongqing region) is located between $105^{\circ} 11^{\prime}-110^{\circ} 11^{\prime} \mathrm{E}$ and $28^{\circ} 10^{\prime}-32^{\circ} 13^{\prime} \mathrm{N}$, covering the lower section of the upper reaches of the Yangtze River (Fig. 1). It covers a total area of $82,400 \mathrm{~km}^{2}$ with a total population of 20.1 million. It has complicated geographic conditions with lower land in the west and higher land in the east; $75.8 \%$ of the region is mountainous, $6.0 \%$ of the region is plains and $18.2 \%$ is hilly, with a variety of ecosystem types, including forest, shrubland, grassland, cropland, river, urbanization, and bare soil. The dominant soil types are purple soil, yellow soil, and paddy soil. The Chongqing region has a subtropical monsoon climate and, for most of the year, it experiences humid conditions with an annual mean temperature of $17-19{ }^{\circ} \mathrm{C}$ and mean minimum and maximum temperatures of $4-8{ }^{\circ} \mathrm{C}$ in January and $26-29^{\circ} \mathrm{C}$ in July, respectively. The mean annual precipitation is approximately $1100 \mathrm{~mm}$. Rainfall is variable in amount and timing, in that $85 \%$ of the annual rainfalls occurs mainly during summer (6-9 months).

\section{Methodology and data collection}

\section{Model description}

Ecosystems such as forests, shrubland, grassland, and so on, impact the timing and magnitude of water flow and water runoff (Guo et al. 2000). These changes can alter hydrological cycles, affecting patterns of evapotranspiration, infiltration, and water retention. Here, we used InVEST including a two-step process to analyze the water flow regulation of ecosystem services. First, the application of a water yield model calculates the average annual water yield (annual average runoff) in each mapped grid cell based on climate data, geomorphological information and land-cover characteristics. The model does not incorporate subsurface or groundwater flow, but assumes that all precipitation becomes surface water runoff without any loss to evapotranspiration. In the second step, water flow regulation is the difference between potential (without the vegetation cover) and actual water yield (under the current ecosystem pattern). The water yield model is based on the Budyko curve (Budyko 1974) and average annual precipitation. Annual water yield for each pixel on the ecosystem was defined as follows:

$Y_{\mathrm{w}}=\left(1-\frac{1+w_{x} \times R_{x j}}{1+w_{x} \times R_{x j}+\frac{1}{R_{x j}}}\right) \times P_{x}$

where $Y_{\mathrm{w}}$ is the annual water yield for each pixel; $P_{x}$ is the annual precipitation in the pixel; $R_{x j}$ is the ratio of potential evapotranspiration to precipitation, which is 


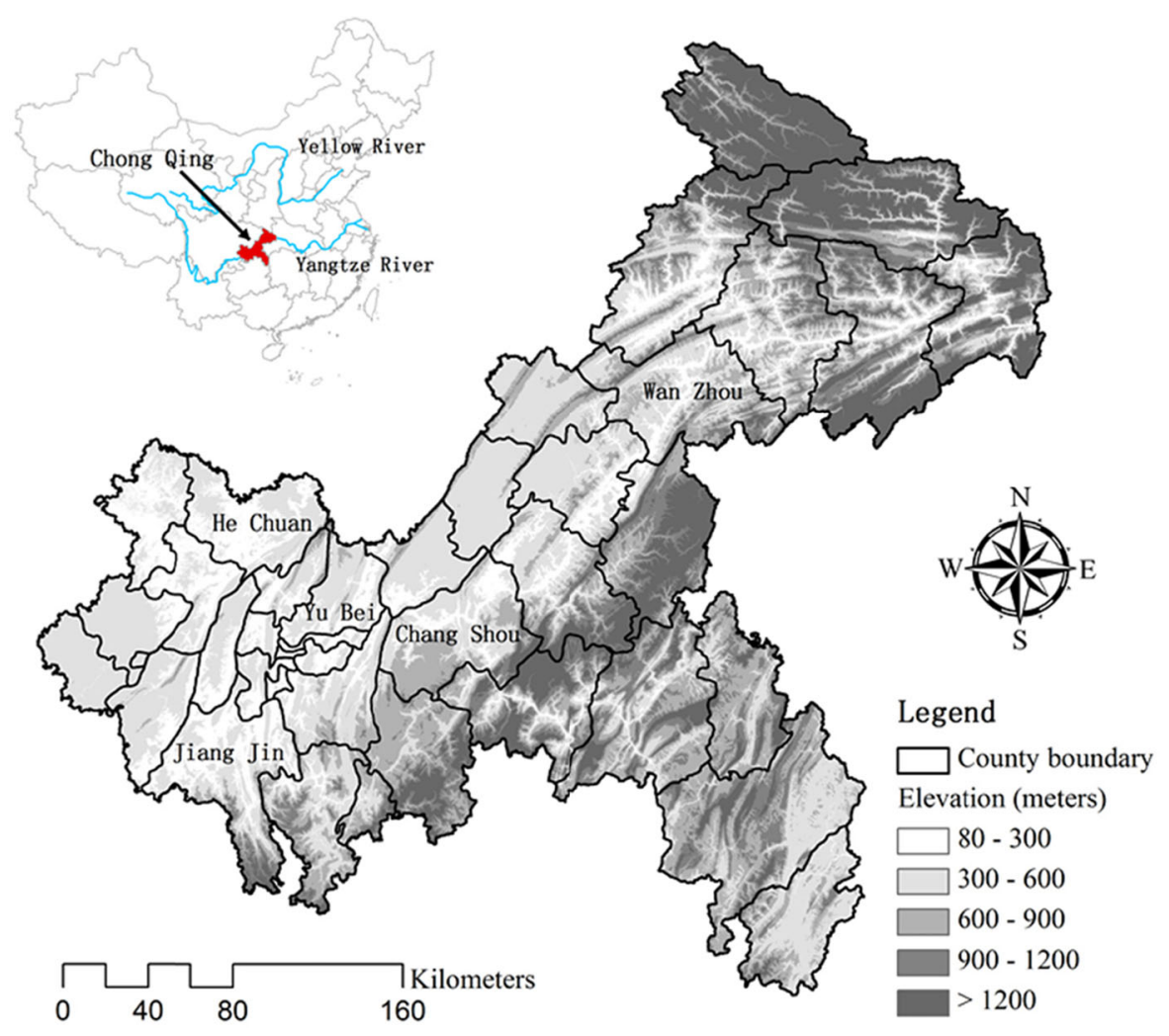

Fig. 1 Location of the study area of Chongqing

the dimensionless Budyko Dryness index on pixel $x$ with ecosystem $j$; and $W_{x}$ is a modified dimensionless ratio of plant-accessible water storage to expected precipitation during the year.

As defined by Zhang et al. 2001, $W_{x}$ is a nonphysical parameter used to characterize natural climatic-soil properties. $W_{x}$ and $R_{x j}$ can be calculated as follows:

$W_{x}=Z \times \frac{\mathrm{AWC}_{x}}{P_{x}}$

$R_{x j}=\frac{k_{x j} \mathrm{ET}_{0 x}}{P_{x}}$

where $\mathrm{AWC}_{x}$ is the plant-available water content (mm). The soil texture and effective soil depth define $\mathrm{AWC}_{x}$, which establishes the amount of water that can be held and released in the soil for use by a plant, estimated as the product of the difference between field capacity and wilting point and the minimum soil depth and root depth. $Z$ is a seasonality factor that represents the seasonal rainfall distribution and rainfall depths ranging from 1 to 10 (Zhang et al. 2001); $k_{x j}$ is the vegetation evapotranspiration coefficient associated with the ecosystem $j$ on pixel $x$; and $\mathrm{ET}_{\mathrm{ox}}$ is the reference evapotranspiration from pixel $x$, and is computed with reference to the Hargreaves equation (Hargreaves et al. 1985; Hargreaves 1994). After repeated validation, when the $Z$ value is 3.0, the water yield is similar to natural runoff.

Based on the above water yield results, the water flow regulation is expressed as:

$W F R=Y_{0}-Y_{\mathrm{v}}$

where WFR is the water flow regulation, which is a consequence of vegetation cover; $Y_{0}$ is the potential water yield without vegetation cover; and $Y_{\mathrm{v}}$ is the actual water yield under the current ecosystem conditions.

Data

Annual precipitation data from 38 meteorological stations during the period 1970-2010 were obtained from the Chinese National Metrological Information Center/ China Meteorological Administration (NMIC/CMA). The average annual precipitation raster value (Fig. 2a) was generated by the application of the kriging 
interpolation method in ArcGIS v9.3, which has been widely used in regionalizing various variables at different scales (Piao et al. 2001; Zhu et al. 2006). Average annual reference evapotranspiration $\left(\mathrm{ET}_{0}\right)$ (Fig. 2b) was obtained using the modified Hargreaves equation, which can generate good results when information is uncertain (Droogers and Allen 2002). This process was completed in interactive data language (IDL) which is a programming language used for data analysis. The soil depth data (Fig. 2c) at a scale of 1:250,000 were acquired from the Institute of Soil Science at the Chinese Academy of Sciences (CAS). Plant-available water content (PAWC) is defined as the difference between the fraction of volumetric field capacity and the permanent wilting point. We used Zhou's method (Zhou et al. 2005) to estimate PAWC (Fig. 2d). Given the large geographic extent of the research area and the complexity of the land surface, it was difficult to meet the accuracy requirements of a maximum likelihood classification (MLC) method alone, which is acknowledged to be one of the most efficient parametric methods for image classification. Therefore, a decision rule-based classification method proposed by Chen and Wang 2010 was adopted. The information on distribution of ecosystem type in 2010 was generated and interpreted based on Landsat MSS and TM satellite remote sensing with an overall accuracy of approximately $82.6 \%$ (Fig. 2e). Each two adjacent temporal images were overlaid in the geographic information system (GIS) software, and the changes in ecosystem were then identified and digitized by visual interpretation, with the help of the sample database. In this way, information on ecosystem changes for three periods $(2000,2005$, and 2010) was extracted. The watershed and subwatersheds (Fig. 2f) were generated by using ArcSWAT and the required shapefile formats based on a SRTM digital elevation model data, which were obtained from the International scientific data service platform. Maximum root depth was obtained from Canadell et al. 1996 and the evapotranspiration coefficient table $\left(K_{\mathrm{c}}\right)$ was estimated based on Allen et al. 1998 and the InVEST user guide.

Moreover, other data, including temperature, carbon dioxide $\left(\mathrm{CO}_{2}\right)$ concentration, gross domestic product proportion (GDP), GDP1 proportion (agricultural (a)

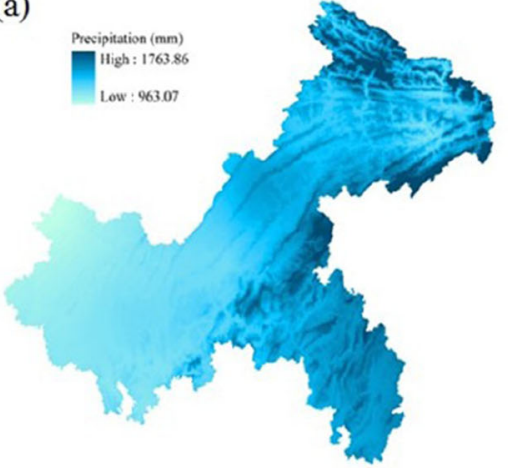

(d)

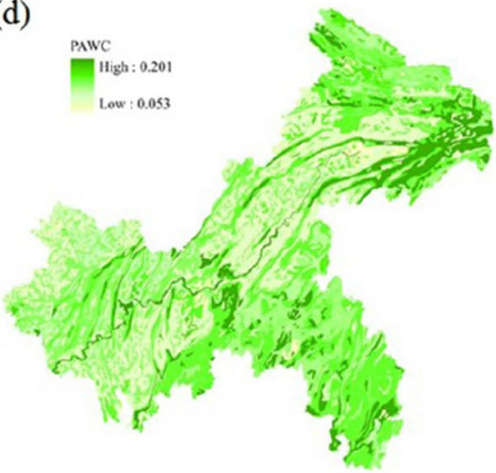

(b)

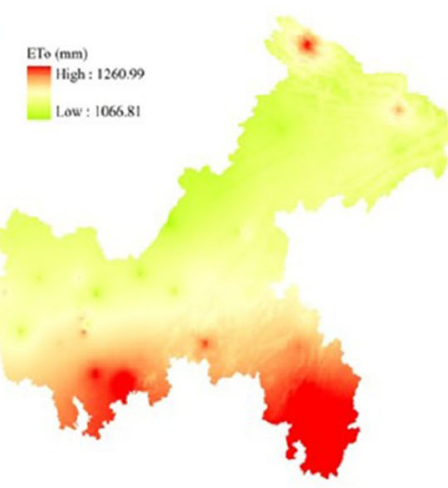

(e)

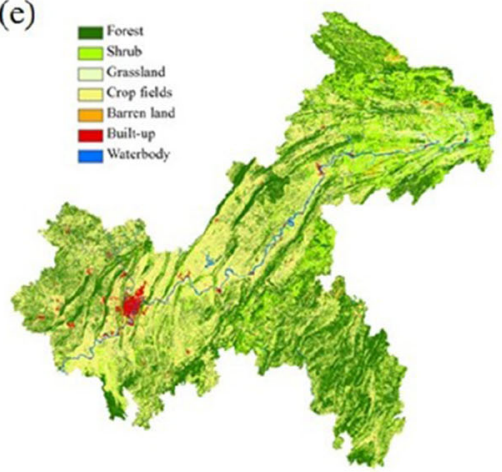

(c)

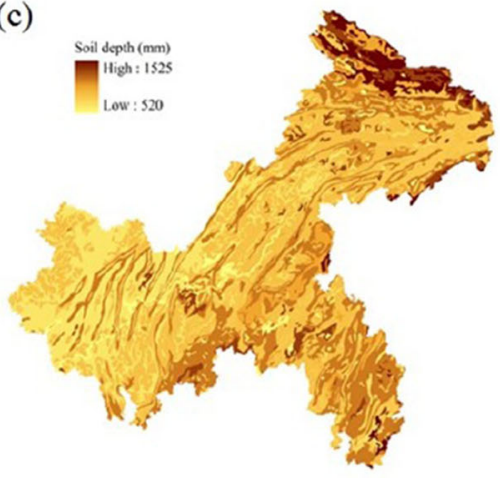

(f)

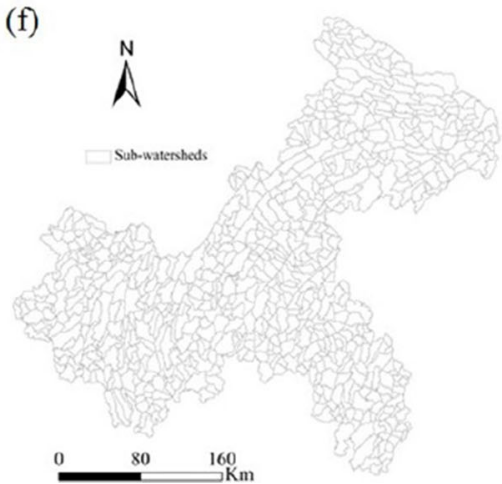

Fig. 2 a Average annual precipitation; b average annual potential evapotranspiration; c soil depth; d plant-available water content; e ecosystem types; and $\mathbf{f}$ watershed and subwatersheds 
GDP), GDP2 proportion (industrial GDP), GDP3 proportion (service industry GDP) and population density, were also collected. The annual temperature from 2000 to 2010 was generated using the Kriging interpolation method. In addition, the annual $\mathrm{CO}_{2}$ concentration data were obtained from the global carbon dioxide concentration model (Guo et al. 2012). In addition, GDP, GDP1, GDP2, GDP3 and population density were collected from statistical yearbooks and the government sector.

\section{Data analyses}

To determine the reasons for changes in water flow regulation during the research period (2000-2010), trend analyses, correlation, and regression analyses were applied. The least-squares linear regression method, which is one of the commonly used methods in trend analysis (Eklundh and Olsson 2003; Stockli and Vidale 2004; Beck et al. 2011), was applied as follows:

$y=a+b \times t+\varepsilon$

where $y$ represents dependent variables, $t$ is year, $a$ and $b$ are fitted variables ( $b$ is the slope as a proxy of trend and $a$ is the intercept), and $\varepsilon$ is the residual error.

For the purpose of exploring the relations among factors including climate, human disturbance, and the variation of water flow regulation, Pearson correlation analyses were applied. We also used a stepwise regression between variation of water flow regulation and impacts (climate and human activities, represented by the temperature, $\mathrm{CO}_{2}$ concentration, GDP density and population density, respectively) to reveal their relative contribution in influencing the variational characteristics of water flow regulation. Given that variables such as precipitation, evapotranspiration, and ecosystem type can be highly autocorrelated with water flow regulation, such variables were not considered. All statistical analyses mentioned above were performed at the county level. The analyses were implemented using SPSS 17.0, and SigmaPlot 11.0.

\section{Results and discussion}

\section{Ecosystem change monitoring}

The dominant ecosystem type in the study area was cropland, and forest was the second major ecosystem type, which occupied around $36.34 \%$ of the study area in 2000 and $38.91 \%$ in 2010 (Fig. 3). Obvious ecosystem changes could be observed during the research period. The area under forest increased by $2.58 \%$, and shrub and grassland increased by 0.11 and $0.56 \%$, respectively, during the 11 -year period. Cropland decreased significantly by approximately $3.30 \%$. Meanwhile, urbanized areas and bodies of water increased slightly ( 0.21 and $0.04 \%$, respectively).

There were changes in ecosystem type across the entire study area, with an uneven distribution (Fig. 4). Most changes occurred in the mountain areas of northeastern and central Chongqing. Cropland represented the main type of change, including a gain and loss accounting for $31.91 \%$ of the total changes from 2000 to 2010 . Moreover, the changes in forest were mainly distributed in northeastern mountain areas, which accounted for $21.87 \%$ of the total change. The change trends of different ecosystem types were not the same (Fig. 4). The net changes in area of each ecosystem were positive in forest, shrub, grassland, built-up and water bodies, but negative in cropland and bare land.

Specifically, the area of forest increased by $2122 \mathrm{~km}^{2}$, from $30,016 \mathrm{~km}^{2}$ in 2000 to $32,138 \mathrm{~km}^{2}$ in 2010. Forests (gradient $>25^{\circ}$ ) in mountainous areas showed more significant changes, whereas forests (gradient $<25^{\circ}$ ) showed little change. From 2000 to 2010, the area of forest (gradient $>25^{\circ}$ ) increased rapidly, with the $1196 \mathrm{~km}^{2}$ of forests being converted from other types of ecosystem, at a rate of approximately $100 \mathrm{~km}^{2} /$ year. Meanwhile, the area of cropland decreased by $2824 \mathrm{~km}^{2}$, from $35,057 \mathrm{~km}^{2}$ in 2000 to $32,333 \mathrm{~km}^{2}$ in 2010 . Cropland (gradient $>25^{\circ}$ ) in mountainous areas showed little change, whereas cropland (gradient $<25^{\circ}$ ) showed more severe changes. From 2000 to 2010 , the area under crops (gradient $<25^{\circ}$ ) decreased rapidly, with $2,018 \mathrm{~km}^{2}$ of cropland being converted to other types of ecosystem, at the rate of approximately $200 \mathrm{~km}^{2} /$ year.

Changes, such as the increase in forest and decrease in cropland, showed that evolution in ecosystem patterns was mainly driven by human activity, especially ecological restoration projects, such as forest engineering, greenbelt construction projects, grain-to-green projects and natural forest protection projects. Especially in areas with steep slopes and at high altitude, where serious soil erosion risks remain, projects included tree planting, aerial planting, returning farmland to forest and grassland, closing 


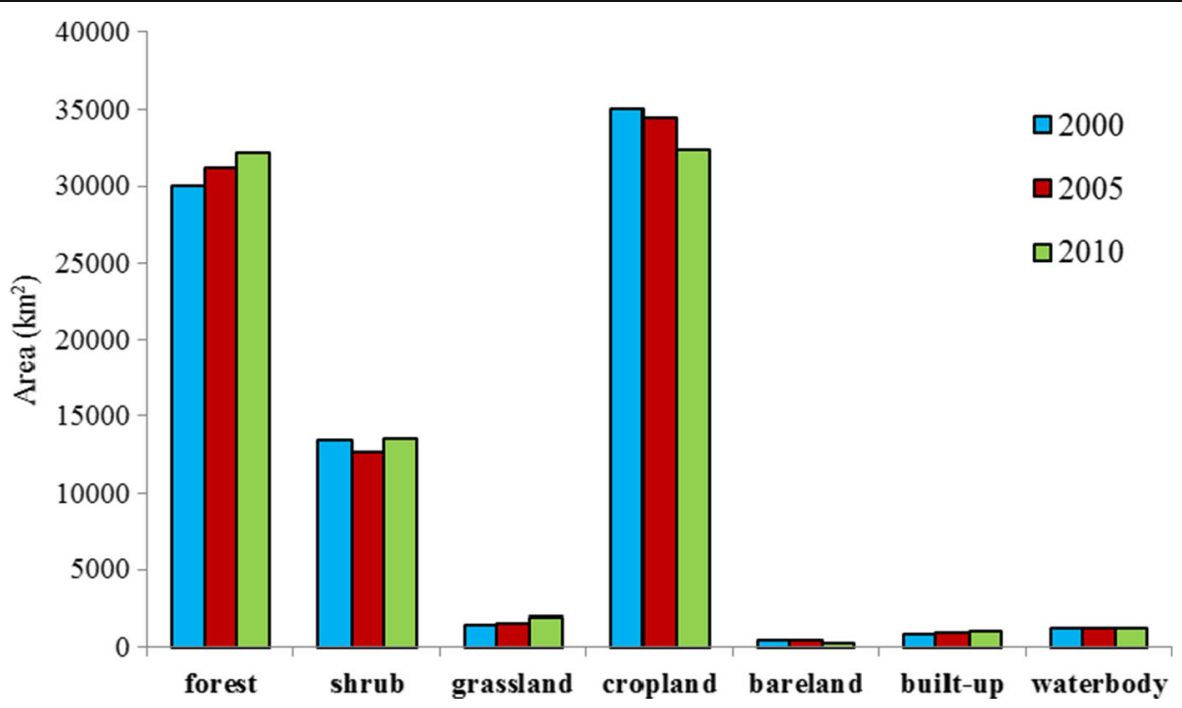

Fig. 3 Area of each ecosystem type in 2000, 2005, and 2010

hillsides to facilitate afforestation and other measures to protect the existing forest resources, and these have been strictly implemented strictly and are taking effect (National Development and Reform Commission NDRC 2005). The distribution of croplands in the areas with gentle slopes and low altitude, coupled with dense population and greater human disturbance, declined rapidly. This is probably the result of a growing population, urbanization, and the development of economy in this area. Specifically, forest engineering projects have accelerated the development of the regional economy, which usually leads to the rapid increase in nursery base areas (i.e., a transition from cropland to shrub and forest) (National Development and Reform Commission NDRC 2005).

Estimation of changes in water flow regulation

\section{Validation of water yield}

In this study, the distribution of water yield (watershed) was modeled using the InVEST model. To verify the reliability of the model, we validated the model results based on observed data collected from hydrometric stations in the study area from 2000 to 2010 . Significant correlations were found between our simulated results and observation-based data (water yield: $r=0.860, p<0.05, n=11)$. These indicated that the InVEST model is applicable to the modeling of water yield across the study area.

\section{Distribution of water flow regulation}

Recently, an ecological restoration program was launched in the Chongqing region, and a large number of crop fields have been converted to forests, shrubs, and grasslands. Meanwhile, urban expansion caused by growth of the human population and development of the economy took over large areas of farmland, and the construction of the Three Gorges Dam led to an increase in area under water. These complicated changes in ecosystem might significantly impact ecosystem structure and services. In this study, we applied the InVEST model and mathematical functions to predict the provision of water flow regulation in 2000, 2005, and 2010. The spatial distribution and dynamic changes from 2000 to 2010 of water flow regulation are shown in Fig. 5. The potential and actual annual water yield in 2010 were calculated to be $8.53 \times 10^{10} \mathrm{~m}^{3}$ and $5.08 \times 10^{10} \mathrm{~m}^{3}$, respectively. Thus, the total amount of water flow regulation was $3.45 \times 10^{10} \mathrm{~m}^{3}$, with a mean capacity of $4145.76 \mathrm{~m}^{3} \mathrm{ha}^{-1}$. Water flow regulation displayed great heterogeneity in terms of its spatial distribution, with mountainous area generally performing better than flat agricultural areas and developed urban areas. Obvious changes could be observed during the research period. The total amount of water flow regulation increased significantly by approximately $2.07 \%$ (the total amount of water flow regulation was $3.38 \times 10^{10} \mathrm{~m}^{3}$ in 2000). Figure $5 \mathrm{c}$ shows the spatial patterns of change in water flow regulation in the study area during the research period. The places with a positive change mainly 


\section{Dynamics 2000-2005}
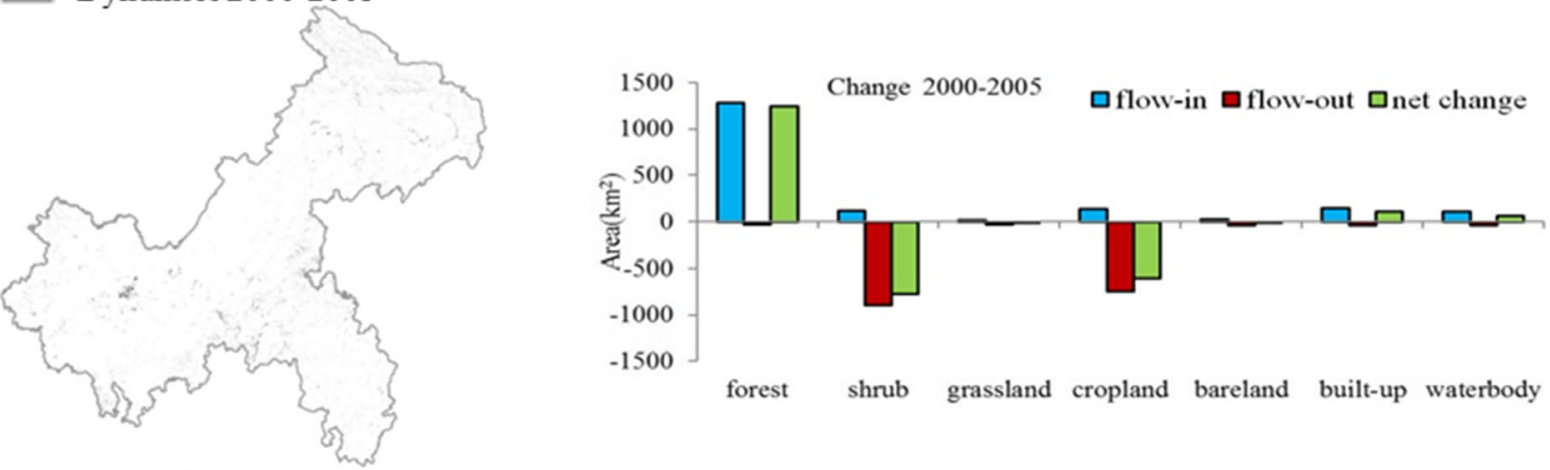

\section{Dynamics 2005-2010}
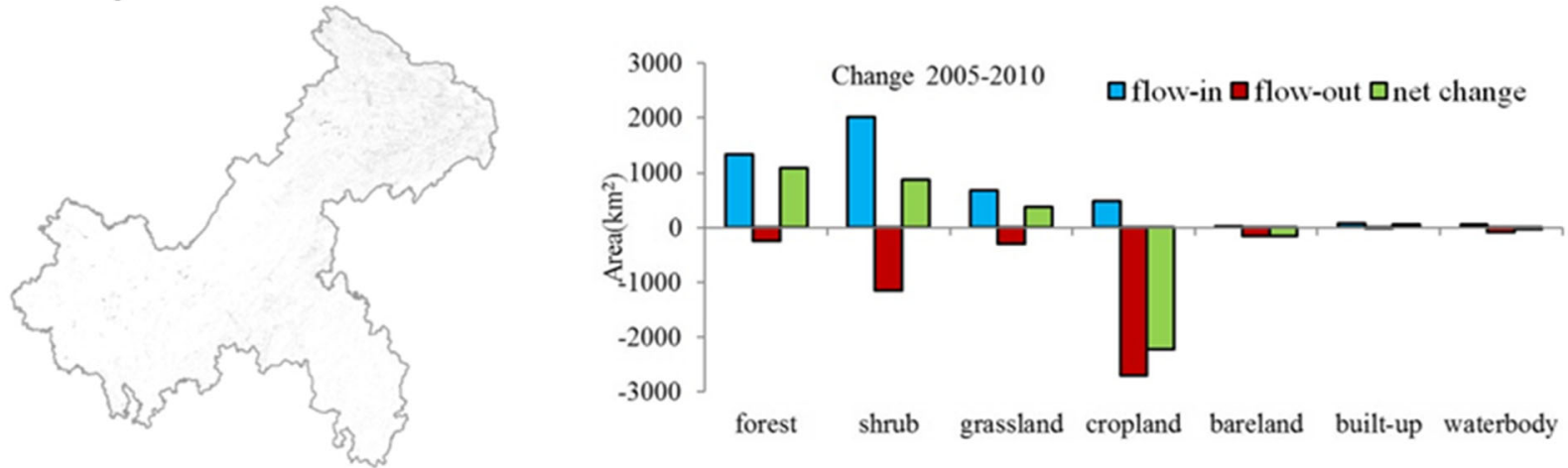

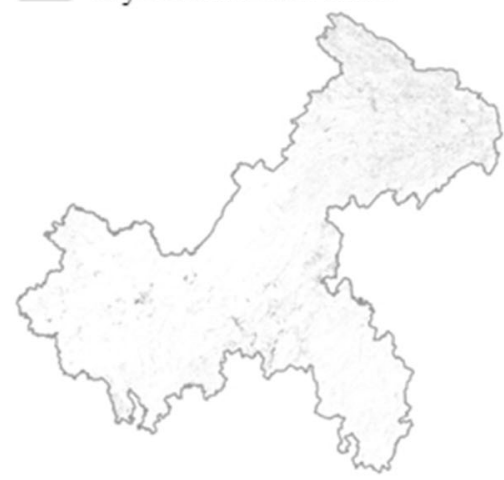

Fig. 4 Map of ecosystem changes from 2000 to 2010 and histogram of net change in area of each cover type (flow-in gain in that other types changed to the highlighted type;

occurred in the high mountain areas in central Chongqing, where the dominant ecosystem category is forest. The places with negative change were mainly distributed in the resettlement areas along the Yangtze River. Decreases in water regulation services were primarily the result of rapid urbanization. Large areas of agricultural land in the peripheral zones surrounding the urban centers were acquisitioned by local governmental departments and developers for urban expansion. Other areas with negative change also appeared in eastern flow-out loss in that the highlighted type changed to other types; net change: the difference between area loss and gain)

Chongqing, close to the reservoir region. This reduction in water flow regulation was the result of a combination of land inundation, rural resettlement, and urban relocation. According to the official reports, the water level of TGRA was $135 \mathrm{~m}$ in June 2003. With the continuous increase in height of the water in the dam, approximately 1.13 million inhabitations will be resettled. Therefore, construction of Three Gorges Dam not only caused a rapid expansion in water body area and built-up areas, but also influenced water flow regulation in the 
(a)

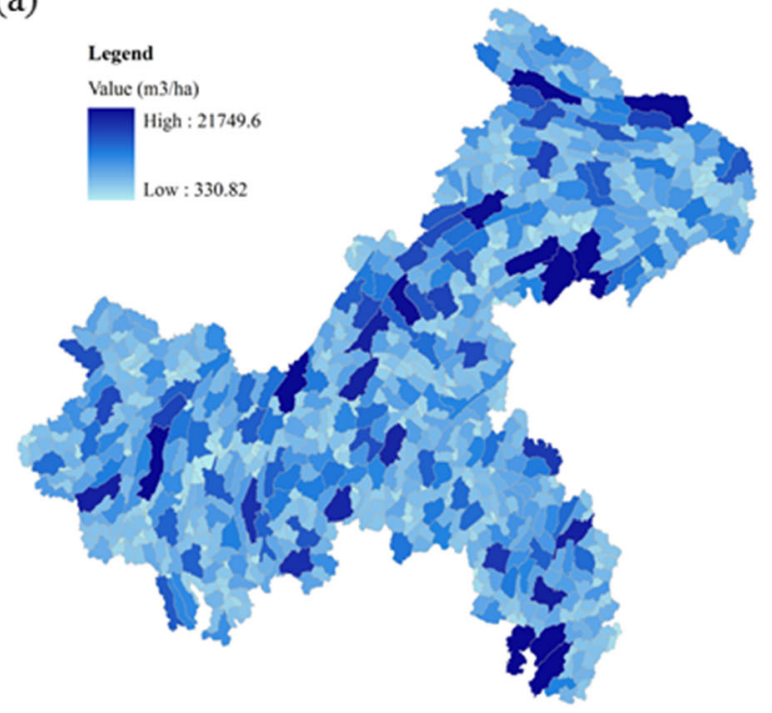

(c)

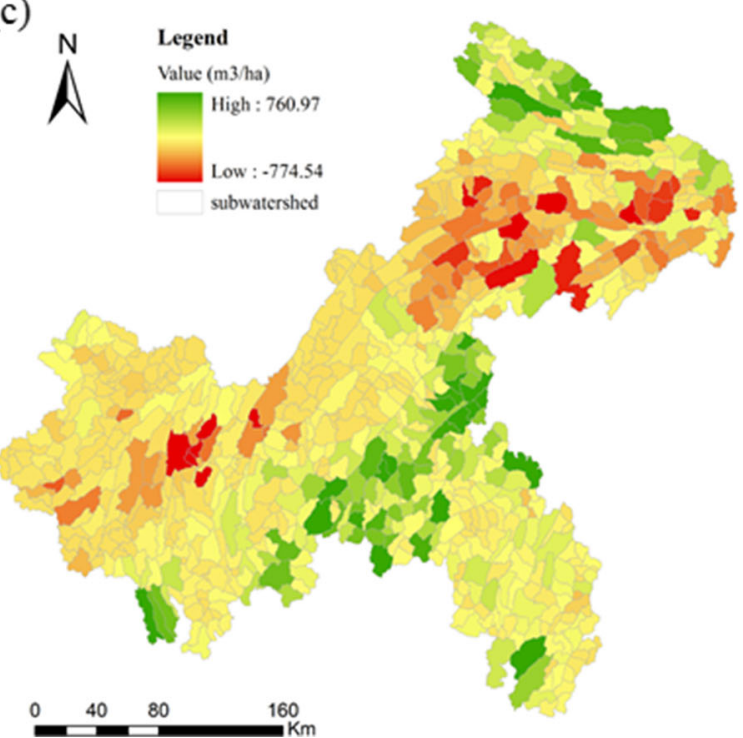

(b)

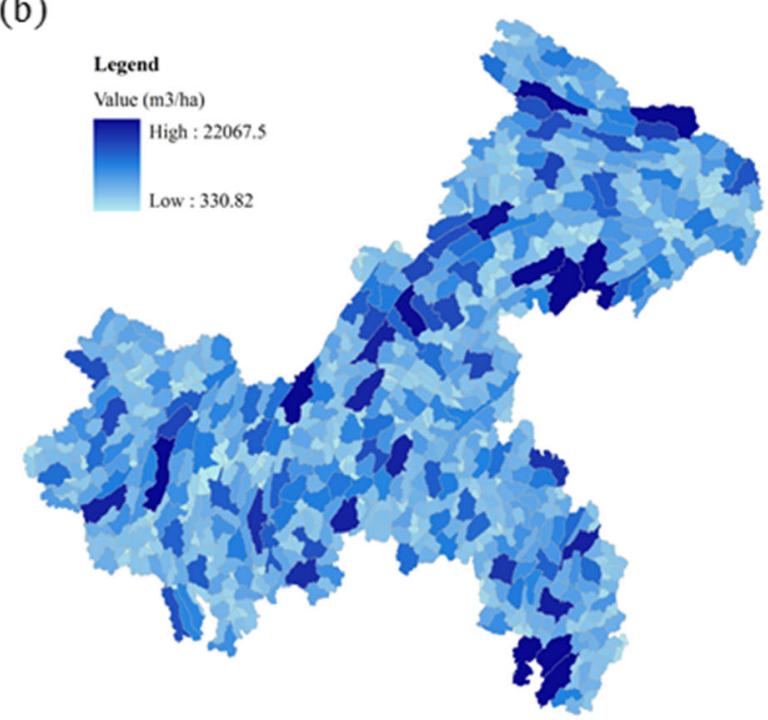

Fig. 5 a Spatial distribution of water flow regulation in 2000 and b 2010 c Change in water flow regulation from 2000 to 2010

surrounding regions because of the large amount of resettlement and population migration.

\section{Influence of topography}

The spatial distribution of the water flow regulation in mountainous areas is significantly affected by topography. The topographic effect can be defined simply as the difference in the amount of water flow regulation at different altitudes and slope positions. In view of the agricultural and urban ecosystems being mainly distributed in low altitude regions in Chongqing, four zones can be defined. These are hilly (elevation below $500 \mathrm{~m}$ ), low mountain (elevation range 500-800 m), middle mountain (elevation range 800-1,200 m), and high mountain zones (elevation above 1,200 m). In addition, the slope angle was divided into four categories: flat slope (less than $5^{\circ}$ ), gentle slope (between $5^{\circ}$ and $15^{\circ}$ ), slanting slope (between $15^{\circ}$ and $25^{\circ}$ ), and steep slope (more than $25^{\circ}$ ).

Comparisons among altitudes (Fig. 6a) showed that ecosystems located in a high mountain zone displayed the highest water flow regulation capacity, followed by those located at middle mountain zones. With regard to 


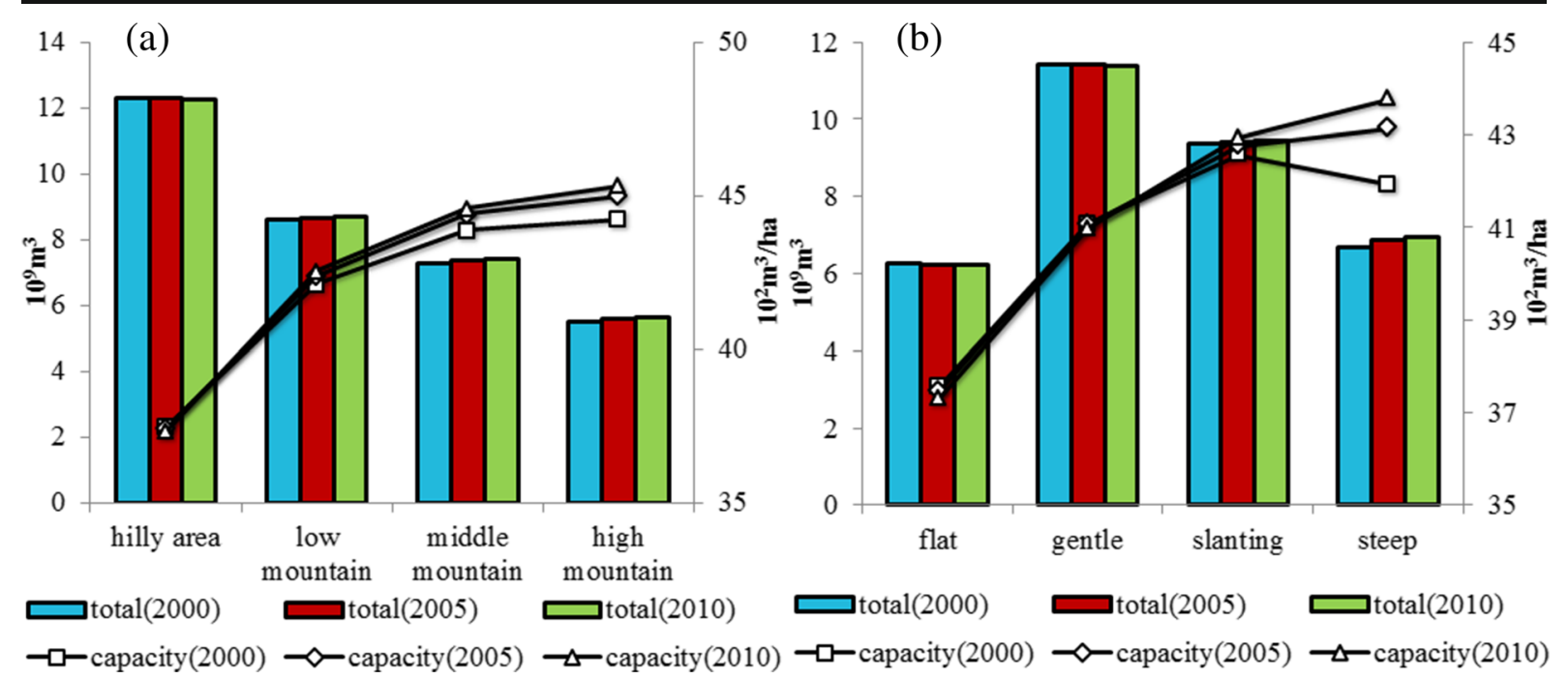

Fig. 6 Amount of water flow regulation at (a) different altitudes and (b) on different slope angles in 2000, 2005, and 2010

quantity, ecosystems in the hilly and low mountain zones regulated more water flow than others, with those in the hilly zone regulating the most (approximately $36.09 \%$ of the total). Although the ecosystem located at the high mountain zone was a relatively minor contributor to the total service, this ecosystem had the highest water flow regulation capacity. In general, the water flow regulation capacity at low mountain, middle mountain, and high mountain zones gradually increased from 2000 to 2010. Specifically, with the increase in altitude, the rate of capacity (the amount of increase accounting for the proportion of capacity in 2000) increased steadily, by $0.97 \%$ in low mountain, $1.64 \%$ in middle mountain, and $2.52 \%$ in high mountain zones. Unlike the distributed structure of water flow regulation with altitude, the amount of the water regulation in the slope zones showed no obvious trend (Fig. 6b). Ecosystem located on gentle slopes provided the largest proportion of the total amount of service (approximately $33.46 \%$ of the total), followed by ecosystems located on slanting slopes.

In addition, the water flow regulation capacity located on slanting slopes and steep slopes gradually increased from 2000 to 2010. Specifically, with the increase in slope angle, the rate of capacity increased rapidly, by $0.81 \%$ on slanting slopes and $4.38 \%$ on steep slopes. These areas (high altitudes and larger slope) with environmental conditions encouraging good vegetation growth (e.g., rainfall, temperature, sunlight, topography, soil nutrients, soil moisture content and less human disturbance) were conducive to the growth of vegetation, and enhancing evapotranspiration. Therefore, improvement in the capacity of water flow regulation at higher altitude and with larger slope values should be the main focus of future management in the study area.

To estimate the change in water flow regulation accurately, it would be necessary to measure the service provision of each ecosystem type. Therefore, observation of changes in the size and percentage contribution of ecosystem categories must be treated with caution. It is clear that, with the increase in altitude and slope, the percentage contribution of forest increased significantly, and the percentage contribution of cropland, by contrast, decreased rapidly (Fig. 7). In 2000, the forest category in the entire area provided the largest fraction of water flow regulation, with a percentage contribution of $43.96 \%$; by 2005 , the total contribution of this category was estimated to have increased by approximately $45.63 \%$, and by approximately $47.80 \%$ by 2010 . Specifically, positive changes were mainly focused on high mountain and steep slope areas, with a 5.52 and $8.80 \%$ net change, respectively. By contrast, the cropland category decreased substantially in the total study area, from $41.14 \%$ in 2000 , to $40.21 \%$ in 2005 , and to $37.10 \%$ in 2010 . Unlike the positive changes, the negative changes were mainly focused on middle mountain and steep slope areas, with a 4.96 and $6.12 \%$ net change, respectively. The sizeable decrease in the contribution of cropland and the concomitant increase in the size of the contribution of the forest category are consistent with the widespread and rapid planting of forests 


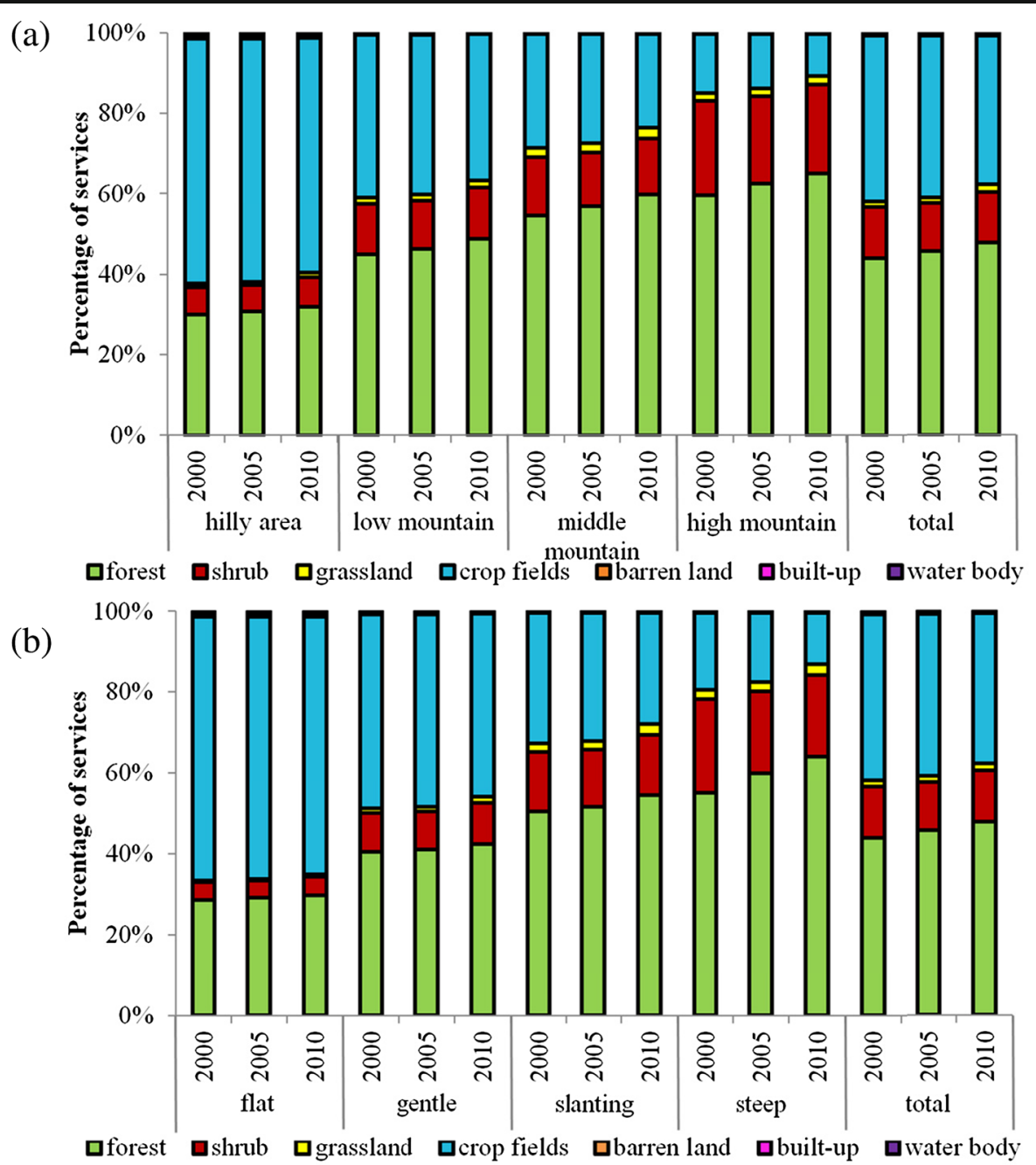

Fig. 7 a Size and percentage of the contribution of each ecosystem category in the altitude zones and the total study area b Size and percentage of the contribution of each ecosystem category in the slope zones and the total study area

in the region and the implementation of some environmental management policies, as $h$ described in the section "Ecosystem change monitoring". The contribution of the shrub category was estimated to have fluctuated from $12.66 \%$ in 2000 , to $11.95 \%$ in 2005 , and to $12.61 \%$ in 2010 . In addition, the contributions of grassland, barren land, urbanized areas, and water body areas were small.

Water flow regulation in Chongqing region was unevenly distributed spatially, because of the vast territory and enormous differences in environmental conditions. Ecosystems located in areas at altitudes of 500-1200 m and slopes of 5-25 demonstrated excellent water flow regulation, thus deserving careful protection in the future.

\section{Influence of climate change and human activities}

The spatial variation characteristics of water flow regulation are formed by interactions between influencing factors (temperature, $\mathrm{CO}_{2}$ concentration, GDP density, and population density). The partial correlation between water flow regulation and temperature or $\mathrm{CO}_{2}$ concentration was positively correlated and statistically significant $(r=0.461, p<0.039$ and $r=0.450, p<0.009$, respectively). By contrast, water flow regulation was negatively correlated with GDP density and population density $(r=-0.399, p<0.022$ and $r=-0.348, p<0.047$, respectively). This correlation could also be observed from the scatter plot based on the unit of county (Fig. 8). Stepwise regression indicated that the $\mathrm{CO}_{2}$ 
(a)

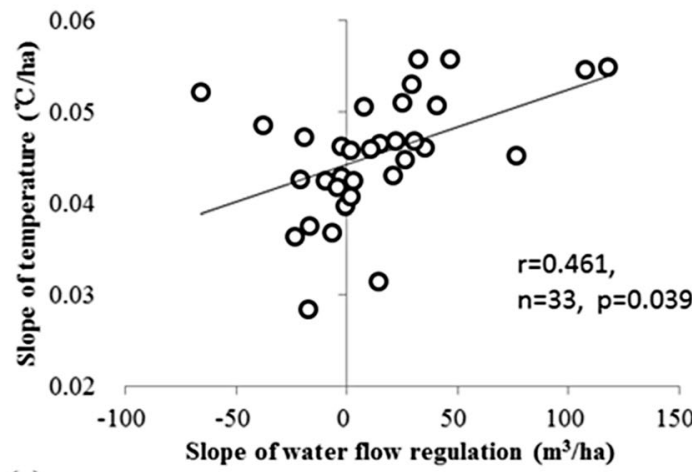

(c)

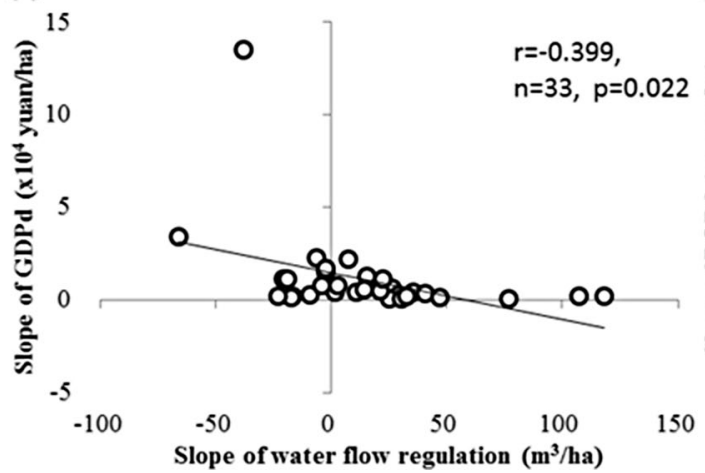

(b)

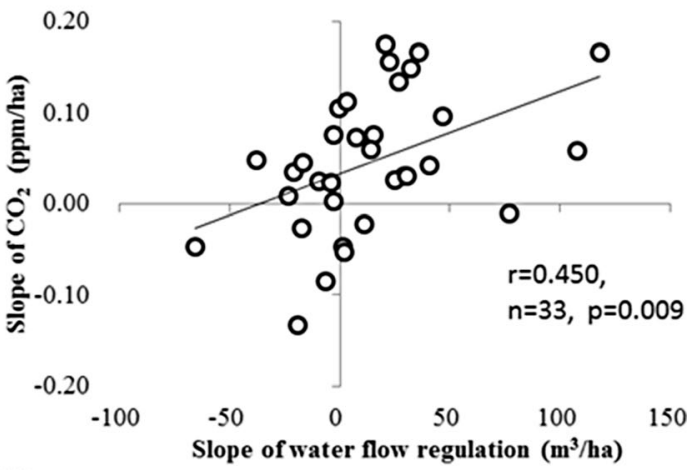

(d)

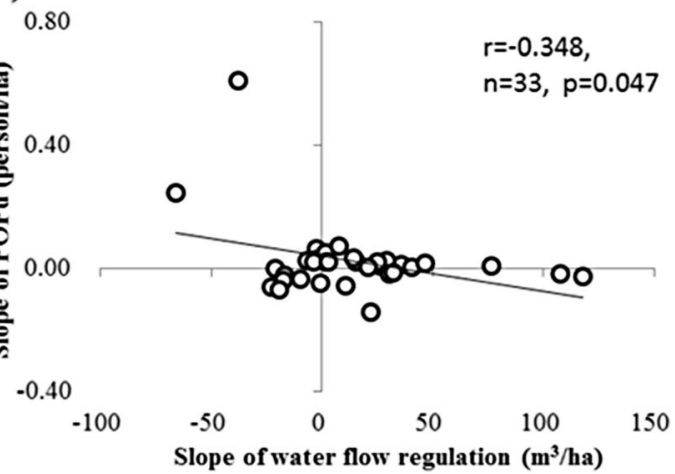

Fig. 8 Relation between water flow regulation and driving factors: a temperature, $\mathbf{b} \mathrm{CO}_{2}$ concentration, $\mathbf{c}$ GDP density, and $\mathbf{d}$ population density from 2000 to 2010 . Each dot represents a county. The line represents the fitted curve

concentration, temperature and GDP density factors could explain all variance in water flow regulation, with the variance contribution reaching $32.72,30.56$ and $36.72 \%$, respectively. Stepwise regression further demonstrated that the variation of water flow regulation in Chongqing region during the research period were primarily controlled by $\mathrm{CO}_{2}$ concentration, temperature and GDP density, whereas the effects of population density were relatively small at the regional scale. It is likely that the increasing $\mathrm{CO}_{2}$ concentration and temperature in the atmosphere is conducive to the growth of vegetation, which will enhance evapotranspiration. It is generally assumed that vegetation growth in alpine regions is sensitive to temperature change (Angert et al. 2005; Zhou et al. 2001; Qin et al. 2014). Rising temperature increases the length of the growing season and increases soil water by melting snow and ice; thus, more days and more water are available for biomass growth. Human activities now comprise nearly one-third to one half of global ecosystem production (Vitousek et al. 1986) and, as development and population pressures continue to mount, these will exert significant pressure on ecosystems. Census-based socioeconomic variables as a main indicator of human activities (e.g., population density and GDP) have shown significant positive effects on urban expansion (Seto et al. 2011; Wu and Zhang 2012), which can disrupt the surface water balance and the partitioning of precipitation into evapotranspiration, runoff, and groundwater flow (Foley et al. 2005). A negative partial correlation was found between water flow regulation and GDP or population density. These findings suggest that GDP and population density have a negative influence on the water flow regulation.

\section{Conclusions}

The ecosystem of the Chongqing region can provide water flow regulation that has significant eco-effects on the downstream TGRA. However, the lack of information on the magnitude of ecosystem service constitutes an obstacle to the understanding of the ecosystems in this region, making it difficult to propose strategies for optimizing ecosystem services. 
Here, we applied the InVEST model and mathematical simulations to estimate the provision of water flow regulation across space and time in 2000, 2005, and 2010. The spatial patterns and impacts of water flow regulation, which are significant in ecosystem conservation and management, were also discussed using spatial analyses and statistical analyses. The results suggest that ecosystems regulated a huge amount of water flow in 2010 , with a total of $3.45 \times 10^{10} \mathrm{~m}^{3}$ of water being regulated annually in Chongqing region. Moreover, the total amount of water flow regulation increased significantly, by approximately $2.07 \%$ from 2000 to 2010 . This growth was partly correlated with extensive ecological restoration policies that resulted in a continuous increase in the area of forest (by $2.58 \%$ ) and a significant decrease in the area of cropland (by $3.30 \%$ ).

In addition, water flow regulation displayed great spatial heterogeneity, with mountainous areas generally performing better than flat agricultural area and developed urban areas. Specifically, ecosystems located in the areas with high altitudes and larger slope demonstrated excellent water flow regulation capacity, thus deserving careful protection and management in the future.

Furthermore, we also analyzed the spatial and time variation in water flow regulation during the research period in different locations (gradient and elevation) in Chongqing region. Locations with positive change in water flow regulation mainly occurred in high mountain areas, and places with negative change were mainly distributed in resettlement areas along the Yangtze River. Furthermore, with the increase in altitude and slope, the percentage contribution of forest increased remarkably; by contrast, the percentage contribution of cropland decreased rapidly. These results provide specific information that could strengthen necessary public awareness of the protection and restoration of ecosystems; this is particularly important given that the spatial variation in water flow regulation in the Chongqing region was significantly affected by climate and human activities at the regional scale.

The processes involved in water flow regulation are complicated. Although we discussed here the regional variations in water flow regulation at different elevations and slopes, the study has several drawbacks, and some parts of the study still need to be exploring further. For example, the spatial heterogeneity of precipitation in different time periods was neglected, the stand structure and growth of forest in regulating ecohydrological functions were also ignored, and some parameters (e.g., evaporation coefficient and root depth) were defined according to the results of previous studies. Furthermore, the calculated results of water flow regulation in this study were not the same as in real terms, but the potential maxima were based on the mathematical models. Nevertheless, it is expected that the simulation methods developed in this study will provide theoretical support for other researchers, and that an increased understanding of the topographic, climatic and anthropogenic impacts on water flow regulation will assist policy, design, assessment, and management in China and other parts of the world.

Acknowledgments This study was funded by National Key Basic Research Program of China (Grant 2009CB421105, 2006CB403402) and Special Foundation from State Key Laboratory of Urban and Regional Ecology. The authors gratefully thank editors and anonymous reviewers for their very helpful comments and constructive feedback.

\section{References}

Allen, R. G., Pereira, L. S., Raes, D., \& Smith, M. (1998). Crop evapotranspiration-guidelines for computing crop water requirements-FAO irrigation and drainage paper 56. Rome: FAO.

Angert, A., Biraud, S., Bonfils, C., Henning, C. C., Buermann, W., Pinzon, J., Tucker, C. J., \& Fung, I. (2005). Drier summers cancel out the $\mathrm{CO}_{2}$ uptake enhancement induced by warmer springs. Proceedings of the National Academy of Sciences of the United States of America, 102, 10823-10827.

Budyko, M. I. (1974). Climate and life. San Diego: Academic.

Bai, Y., Zhuang, C. W., Ouyang, Z. Y., Zheng, H., \& Jiang, B. (2011). Spatial characteristics between biodiversity and ecosystem services in a human-dominated watershed. Ecological Complexity, 8(2), 177-183.

Beck, H. E., McVicar, T. R., van Dijk, A. I., Schellekens, J., de Jeu, R. A., \& Bruijnzeel, L. A. (2011). Global evaluation of four AVHRR-NDVI data sets: intercomparison and assessment against Landsat imagery. Remote Sensing of Environment, $111,2547-2563$.

Canadell, J., Jackson, R. B., Ehleringer, J. B., Mooney, H. A., Sala, O. E., \& Schulze, E. D. (1996). Maximum rooting depth of vegetation types at the global scale. Oecologia, 108(4), 583595.

Costanza, R., D'Arge, R., de Groot, R., Farber, S., Grasso, M., Hannon, B., Limburg, K., Naeem, S., O’Neill, R. V., Paruelo, J., Raskin, R. G., Sutton, P., \& van den Belt, M. (1997). The value of the world's ecosystem services and natural capital. Nature, 387, 253-260.

Chen, Z. H., \& Wang, J. F. (2010). Land use and land cover change detection using satellite remote sensing techniques in the mountainous Three Gorges area, China. International Journal of Remote Sensing, 31(6), 1519-1542. 
Chen, L., Xie, G. D., Zhang, C. S., Pei, S., \& Fan, N. (2011). Modelling ecosystem water supply services across the Lancang river Basin. Journal of Resources and Ecology, 2(4), 322-327.

Daily, G. C. (Ed.). (1997). Nature's services: societal dependence on natural ecosystems. Washington DC: Island Press.

De Groot, R. S., Wilson, M. A., \& Boumans, R. M. J. (2002). A typology for the classification, description and valuation of ecosystem functions, goods and services. Ecological Economics, 41, 393-408.

Droogers, P., \& Allen, R. G. (2002). Estimating reference evapotranspiration under inaccurate data conditions. Irrigation and Drainage Systems, 16, 33-45.

Eklundh, L., \& Olsson, L. (2003). Vegetation index trends for African Sahel 1982-1999. Geophysical Research Letters, 30, 1430-1433.

Foley, J. A., DeFries, R., Asner, G. P., Barford, C., Bonan, G., Carpenter, S. R., Chapin, F. S., Coe, M. T., Daily, G. C., Gibbs, H. K., Helkowski, J. H., Holloway, T., Howard, E. A., Kucharik, C. J., Monfreda, C., Patz, J. A., Prentice, I. C., Ramankutty, N., \& Snyder, P. K. (2005). Global consequences of land use. Science, 309, 570-574.

Guo, Z. W., Xiao, X. M., \& Li, D. M. (2000). An assessment of ecosystem services: water flow regulation and hydroelectric power production. Ecological Applications, 10(3), 925-936.

Guo, Z. W., Xiao, X. M., Gan, Y. L., \& Zheng, Y. J. (2001). Ecosystem functions, services and their values - a case study in Xingshan county of China. Ecological Economics, 38, 141-154.

Guo, M., Wang, X. F., Li, J., Yi, K. P., Zhong, G. S., \& Tani, H. (2012). Assessment of global carbon dioxide concentration using MODIS and GOSAT data. Sensors, 12, 16368-16389.

Hewlett, J. D. (1982). Principles of forest hydrology. Athens: University of Georgia Press.

Hargreaves, G. L., Hargreaves, G. H., \& Riley, J. P. (1985). Agricultural benefits for Senegal river basin. Journal of Irrigation and Drainage Engineering ASCE, 111(2), 113-124.

Hargreaves, G. H. (1994). Defining and using reference evapotranspiration. Journal of Irrigation and Drainage Engineering ASCE, 120(6), 1132-1139.

Hillel, D. (1991). Out of the earth: civilization and the life of the soil. New York: Free Press.

Hunter, L. M., Manuel, D. J., Gonzalez, G., Matt, S., Kimberly, S. K., Richard, T., Thomas, C., Edwards, J., Robert, J. L., \& Mary, C. (2003). Population and land use change in the California Mojave: natural habitat implications of alternative futures. Population Research and Policy Review, 22(4), 373397.

Miao, C. Y., Ni, J. R., \& Borthwick, A. G. L. (2010). Recent changes of water discharge and sediment load in the Yellow river basin, China. Progress in Physical Geography, 34(4), 541-561.

Miao, C. Y., Ni, J. R., Borthwick, A. G. L., \& Yang, L. (2011). A preliminary estimate of human and natural contributions to the changes in water discharge and sediment load in the Yellow river. Global and Planetary Change, 76(3-4), 196-205.

Miao, C. Y., Duan, Q. Y., Sun, Q. H., Huang, Y., Kong, D. X., Yang, T. T., Ye, A. Z., Di, Z. H., \& Gong, W. (2014). Assessment of CMIP5 climate models and projected temperature changes over Northern Eurasia. Environmental Research Letters, 9, 055007.
National Development and Reform Commission (NDRC) (2005). The greenshelt construction project around the Three Gorges Reservoir (in Chinese). http://www.sdpc.gov.cn/zjgx/ t20050715_36863.htm.

Piao, S. L., Fang, J. Y., \& Guo, Q. H. (2001). Application of CASA model to the estimation of Chinese terrestrial net primary productivity. Acta Phytoecologica Sinica, 25, 603-608.

Qin, Y., Yi, S., Ren, S., Li, N., \& Chen, J. (2014). Responses of typical grasslands in a semi-arid basin on the QinghaiTibetan plateau to climate change and disturbances. Environmental Earth Sciences, 71, 1421-1431.

Semwal, R. L., Nautiyal, S., Sen, K. K., Rana, U., Maikhuri, R. K., Rao, K. S., \& Saxena, K. G. (2004). Patterns and ecological implications of agricultural land-use changes: a case study from central Himalaya, India. Agriculture Ecosystems and Environment, 102, 81-92.

Stockli, R., \& Vidale, P. L. (2004). European plant phenology and climate as seen in a 20-year AVHRR land-surface parameter dataset. International Journal of Remote Sensing, 25, 33033330 .

Seto, K. C., Fragkias, M., Güneralp, B., \& Reilly, M. K. (2011). A meta-analysis of global urban land expansion. PLoS ONE, 6(8), e23777.

Vitousek, P. M., Ehrlich, P. R., Ehrlich, A. H., \& Matson, P. A. (1986). Human appropriation of the products of photosynthesis. Bioscience, 36, 368-373.

Wu, K., \& Zhang, H. (2012). Land use dynamics, built-up land expansion patterns, and driving forces analysis of the fastgrowing Hangzhou metropolitan area, eastern China (19782008). Applied Geography, 34, 137-145.

Wang, S. X., Wu, B., \& Yang, P. N. (2014). Assessing the changes in land use and ecosystem services in an oasis agricultural region of Yanqi Basin, Northwest China. Environmental Monitoring Assessment, 186, 8343-8357.

Zhang, L., Dawes, W. R., \& Walker, G. R. (2001). Response of mean annual evapotranspiration to vegetation changes at catchment scale. Water Resources Research, 37, 701-708.

Zhou, L. M., Tucker, C. J., Kaufmann, R. K., Slayback, D., Shabanov, N. V., \& Myneni, R. B. (2001). Variations in northern vegetation activity inferred from satellite data of vegetation index during 1981 to 1999. Journal of Geophysical Research-Atmospheres, 106, 20069-20083.

Zhou, W. Z., Liu, G. H., Pan, J. J., \& Feng, X. F. (2005). Distribution of available soil water capacity in China. Journal of Geographical Sciences, 15(1), 3-12.

Zhu, W. Q., Pan, Y. Z., He, H., Yu, D. Y., \& Hu, H. B. (2006). Simulation of maximum light use efficiency for some typical vegetation types in China. Chinese Science Bulletin, 51, 457463.

Zhang, J. X., Liu, Z. J., \& Sun, X. X. (2009). Changing landscape in the three gorges reservoir area of Yangtze river from 1977 to 2005: Land use/land cover, vegetation cover changes estimated using multi-source satellite data. International Journal of Applied Earth Observation and Geoinformation, 11(6), 403-412.

Zhang, B., Li, W. H., Xie, G. D., \& Xiao, Y. (2010). Water conservation of forest ecosystem in Beijing and its value. Ecological Economics, 69(7), 1416-1426.

Zhang, B., Xie, G. D., Yan, Y. P., \& Yang, Y. G. (2011). Regional differences of water conservation in Beijing's forest ecosystem. Journal of Forestry Research, 22(2), 295-300. 